our world is a world of stages, and yet who do not see how something other than local properties could constrain causal relations. ${ }^{2}$

The University of Sydney

Sydney, Australia 2006

dbm@mail.usyd.edu.au

The University of Queensland

Brisbane, Australia 4072

kristie_miller@yahoo.com

\title{
References
}

Lewis, D. 1983. Philosophical Papers I. Oxford: Oxford University Press.

Noonan, H. 2003. A flawed argument for perdurance. Analysis 63: 213-15.

van Inwagen, P. 2000. Temporal parts and identity across time. The Monist 83: 437-59.

2 Thanks, as so often, to Denis Robinson for very helpful discussion of these issues, as well as to an anonymous referee for this journal.

\section{Dion, Theon, and the many-thinkers problem}

\section{Michael B. Burke}

My solution to the problem of Dion and Theon (Burke 1994a) employs the doctrine of sortal essentialism. ${ }^{1}$ Jim Stone (2002) objects to my solution and proposes to weaken the doctrine so as to block my employment of it. Others question a different element of my solution: the maximality of personhood and thinkerhood. After opposing Stone's weakening of sortal essentialism, and responding in a preliminary way to the objection that motivates it, I outline a novel, conservative solution to the related 'many-thinkers problem', one that fortifies all of the elements of my solution to the problem of Dion and Theon. ${ }^{2}$

${ }^{1}$ I take the doctrine to assert that for every object there is a property, a sortal property, such that (a) to know that the object has that property is to know what the object is, and (b) it's metaphysically impossible for the object to exist without having that property.

2 Other critics of my solution include Olson (1997), Carter (1997), Lowe (2002: 68, 74-76), Noonan (1999), Sidelle (2002: 127-29) and Sider (2001: 161-65), among others. One supporter is Rea (2000). 
1. Dion is a whole-bodied, human person. Theon is that part of Dion which consists of all of Dion except his left foot. Now Dion's left foot has been successfully amputated. Presumably, Dion has survived the amputation. But so, presumably, has Theon, from which no part was removed. Dion and Theon still differ numerically, since there is something true of Dion but false of Theon: that he was diminished by the surgery. Evidently, then, Dion and Theon are now 'coinciding objects'. That is, they are different objects that now are composed of exactly the same matter and occupy exactly the same place, which seems absurd. And since Theon is now identical in its microphysical properties to the person Dion, it seems that Dion and Theon must now be coinciding persons, which seems even more absurd. Hence we have a problem.

There are many solutions on offer. (For a survey, see Burke 1994a: \$I.) Notoriously, all have features that at least initially seem counterintuitive. On my solution, Dion survives the surgery but Theon perishes. So there is no post-surgical coincidence. What raises eyebrows, of course, is my claim that Theon perishes. After all, Theon seems to undergo no intrinsic change (or none of significance). Theon seems to undergo merely a relational change, a 'Cambridge change'.

That Theon does indeed perish (if it exists in the first place $^{3}$ ) follows (given the assumptions I'll identify) from three premisses, each of which accords with ordinary ways of thinking. The first premiss - call it the maximality premiss - is that proper parts of men are not themselves men. Given the maximality premiss (and given the assumption that there is a man of whom Theon is a proper part), we can say that Theon is initially a non-man. The second premiss - call it the essentialist premiss - is that men (humans) are essentially men, ${ }^{4}$ from which it follows (in S5) that nonmen are essentially non-men. Given the essentialist premiss as well as the maximality premiss, we can say that Theon is a non-man essentially. This means, presumably, that Theon cannot change from being a non-man to being a man. (When I speak of something's changing from $F$ to $G$, or of an F's becoming a $G$, I mean numerically the same thing's being first an $F$ and then a $G$.) The third premiss - the no-coincidence premiss - is that no two objects coincide. (We would need to surrender this commonsen-

${ }^{3}$ Although I doubt the assumption that it does, I don't dispute the assumption, because I don't doubt the existence of Dion's head, brain or CNS, any of which might take the place of Theon in a reformulation of the problem.

${ }^{4}$ The formulation is Stone's. Just for the purposes of this reply, I'll accept Stone's revision of my essentialist premiss, which had been that persons are essentially persons. (On my view, persons are beings that are or were rational, actually or potentially.) In truth, I doubt that men are essentially men, because I think that a man might survive a transformation from human person to non-human person. 
sical assumption only if we could find no other, more congenial means of dealing with such problems as that of Dion and Theon. ${ }^{5}$ ) Given the nocoincidence premiss (and given an endurantist conception of persistence), we can say that if Theon survives its separation from Dion's left foot, Theon survives as a man. That's because there clearly is some man where a surviving Theon would be (whether he's Dion, Theon, or someone else). So if there can't be two objects there, a surviving Theon would have to be that man. Given all three plausible premisses (and the auxiliary assumptions), we can conclude that Theon does not survive. To survive, Theon would have to do what nothing can do: go from being a non-man to being a man.

2. Stone accepts all three premisses (and the auxiliary assumptions), at least for the sake of argument (2002: 217), and he finds no error in my logic. But like most of my critics, Stone finds my conclusion unacceptably counterintuitive.

The lesson Stone draws from my argument is that we should rethink the import of the essentialist premiss. He allows that men are essentially men and that non-men are essentially non-men, but suggests that we construe these theses so as to allow for some cases in which men become non-men and some cases in which non-men become men. A man can't become an ox, and an eggplant can't become a man. But when,

owing to the maximality of the concept man and a Cambridge change (being placed at a greater distance from Dion's left foot), non-man Theon becomes a man, this must be counted as 'the exception that proves the rule' if essentialism is to be taken seriously. (2002: 219)

Stone says that, as applied to animals, 'sortal essentialism derives its plausibility from cases where sortal change corresponds to a profound change in the inner principle from which most of an animal's characteristics flow' (218). But Theon undergoes no change in that inner principle, Stone says, when changing from non-man to man. Before the change as well as after, Theon's explanatory inner principle is 'the form Man' or, 'in more contemporary terms', its 'genetic code' (219). Stone then offers (complicated) construals of the essentialist theses of interest (219-20), construals on which Theon's surviving the transition from non-man to man is compatible with the thesis that non-men are essentially non-men.

${ }^{5}$ In Burke 1997, using arguments similar to those of Burke 1994a, I seek to remove the principal obstacles to identifying human persons with human bodies/organisms/ animals. We who assert such identities are as free as anyone else, I argue, to accept a partially psychological criterion of personal identity physical. 
3. Even if my claim that Theon perishes were as implausible as Stone believes, the alternative he offers would succeed only in moving us from the frying pan into the fire. Given the endurantist view of persistence implicit in Stone's article (a view that I share), the claim that Theon survives and becomes a man is itself highly implausible. For if Theon becomes a man, Theon becomes some particular man. Theon becomes Dion, or else a man other than Dion. Regrettably, Stone doesn't say which. (The reason, no doubt, is that he isn't offering a solution to the problem of Dion and Theon.) If Theon becomes Dion, then two (enduring) things become one, an idea that few philosophers find coherent, never mind plausible. If, on the other hand, Theon becomes a man other than Dion, then, unless Dion perishes, Dion and Theon come to be coinciding men. In short, Stone offers us no refuge from implausibility.

Lest it be thought that Stone might profitably convert to perdurantism, I will show that perdurantists too seem ill-positioned to say that Theon becomes a man. Suppose, first, that manhood is maximal. Then the postsurgical temporal part of Theon is not a man. That's because it is numerically identical with the post-surgical temporal part of Dion, and is therefore a proper (temporal) part of a man. Suppose now that manhood is not maximal. Then even the pre-surgical temporal part of Theon is a man. That's because the pre-surgical temporal part of Dion is (presumably) a man, and because the pre-surgical temporal part of Theon is (presumably) a sufficiently inclusive (spatial) part of that man. So, whether manhood is maximal or not, Theon evidently does not undergo a change from nonman to man.

4. Thus far I have argued that nothing is gained by Stone's weakening of sortal essentialism, at least not so far as Stone has shown. Now I will seek to elicit the plausibility of the allegedly implausible conclusion that the weakening is designed to block: that Theon ceases to exist when separated from Dion's foot. First I'll rehearse, briefly, points I've made before, some of which Stone and other critics have neglected. Then I'll add a new point: that the microphysical differences between the pre-surgical Dion and the pre-surgical Theon, and between the pre-surgical Theon and the Theonshaped object left by the surgery, are far more significant than previously appreciated. (I won't consider whether they reflect a difference in 'inner principle'.) The new point will enhance the credibility both of my maximality premiss and of my 'incredible' conclusion. Less directly, the point will buttress the other two premisses as well: whatever mitigates the counterintuitiveness of a conclusion contributes to the acceptability of premisses that lead to the conclusion.

On first hearing, it does seem incredible that Theon perishes. But that's because we focus, when mentally comparing the pre-surgical Theon and 


\section{MICHAEL B. BURKE}

the surgery's survivor, on what they have in common: their shape and their composition. (That there aren't two, coinciding survivors, Dion and Theon, is a continuing assumption which there will be no pressure to surrender if I can make it plausible that Theon perishes.) What easily escapes our attention, because it must be grasped by the intellect rather than the imagination, is the difference in sort: The survivor is a man, whereas the pre-surgical Theon is not.

Stone, of course, does attend to the difference in sort, but still finds it incredible that Theon is destroyed by the surgery. He refers to the change resulting in Theon's sortal change as that of 'being placed at a greater distance from Dion's left foot' and calls it 'trivial' (2002: 218). I want to note that if a trivial change results in Theon's changing from non-man to man, this shows that trivial changes can be consequential.

Still, it may seem implausible that Theon's separation from Dion's foot results in Theon's demise. If so, consider this: Just as man is maximal, thinking is maximal. (I use 'thinking' in the broad, Cartesian sense, in which it applies to all conscious mental activity.) The pre-surgical Theon is a non-man that neither perceives, emotes, nor reasons. (The perfectly ordinary man Dion doesn't contain a multitude of thinkers.) During the surgery, of course, Theon neither matures nor recovers from an incapacitating ailment. Theon's parts survive, but the object they compose after the surgery is a perceiving, emoting, reasoning man. The Theon-shaped object left by the surgery is both sortally and psychologically discontinuous with Theon.

If Stone and other critics will ponder the points of the last three paragraphs, they should find it much less implausible that Theon perishes, providing they accept my maximality claims. Stone allows that the presurgical Theon is a non-man, but does not address my claim that it's also a non-thinker. Others, however, have questioned that claim. (See, for example, Carter 1997; Olson 1997; and Sider 2001: 161-65.) After all, the pre-surgical Theon has the very same functioning brain as does the thinker Dion. And the pre-surgical Theon is all but identical in its microphysical properties to the Theon-shaped thinker left by the surgery. Since it seems plausible that the thinkerhood of an object depends on its microphysical properties alone, there is pressure to say that Theon is a thinker, if not a man, even before the surgery. Some theorists resist the pressure by joining van Inwagen (1981) in denying that there is any such object as Theon in the first place. (See Olson 1995 and Merricks 2001: 47-53.) This strategy is plausible enough as applied to Theon, but far less plausible as applied to Dion's head, brain, or CNS, any of which might take the place of Theon in a reformulation of the problem. Alternatively, one might yield to the pressure, and seek to mitigate the counterintuitiveness of doing so by relativizing identity (Geach 1962: 215-18) or graduating identity 
(Lewis 1993: 33-34). Few of us, however, wish to relinquish the standard conception of identity.

5. This problem - that of either forestalling a multiplication of thinkers or else making the multiplication less disagreeable than it initially seems - has come to be called the many-thinkers problem. In the space that remains, I will outline a novel, conservative solution to it, one on which heads, brains, cerebra, central nervous systems, and, perhaps, such arbitrary parts as Theon do indeed exist, but don't think. The solution will serve as well to reinforce my solution to the problem of Dion and Theon. (For a presentation with additional details, see Burke 2003, where I address the many-thinkers problem exclusively.)

Although (the pre-surgical) Theon contains the same functioning brain as does the (pre-surgical) thinker Dion, there are differences between Dion and Theon that can explain why only Dion is a thinker. First I'll cite those differences, all of which stem from their microphysical differences (i.e. differences in the qualities and interrelations of their microphysical parts). Then I'll explain why the differences cited are plausibly sufficient to ground a difference with respect to thinkerhood. (There are corresponding, equally pronounced differences between the pre-surgical Theon and the Theon-shaped object left by the surgery.) For ease of expression I'll use personal pronouns when speaking of any thinker, even though it's an open question whether thinking person-parts would qualify as 'persons'.

(1) Dion is an organism; Theon is not. (I believe that the maximality of organism will be granted even by those who question the maximality of thinker. See, for example, Olson 1997: 261.) This difference is important if only because it helps to explain the other differences.

(2) The I-thoughts constituted by events occurring within the brain shared by Dion and Theon are differentially true of Dion. That is, many of the I-thoughts are true only of Dion ('I am a whole-bodied man'; 'I am called Dion'; 'I weigh 80 kilos, not 79 kilos'; 'I am [or my body is] an organism'; 'I have a sore toe'), whereas none is true only of Theon (unless its subject is misinformed about the properties of the 80-kilo object that he takes to be his body). Plausibly, these facts make it the case, or help to make it the case, that Dion alone is the subject of the I-thoughts.

(3) There is someone who is directly aware of all and only those (tactile and kinaesthetic) sensations felt in some part of Dion. But anyone who is directly aware of sensations felt in some part of Theon is directly aware, in a natural, normal way, of sensations felt in something (a foot) that lies outside of Theon.

(4) There is someone who has direct voluntary control over all and only those parts of Dion over which anyone has direct voluntary control. But anyone who has direct voluntary control over any part of Theon has direct 
voluntary control, in a natural, normal way, over something that lies outside of Theon.

Apropos of differences (3) and (4), note that it's plausibly a conceptual truth that the 'body' of a thinker includes anything in which the thinker feels sensations, in a natural, normal way, and over which the thinker has, in a natural, normal way, direct voluntary control. Plausibly, Theon fails to be a thinker in virtue (or partly in virtue) of failing to contain as a part everything in which it would feel sensations, and over which it would have direct voluntary control, if it were a thinker.

(5) There is someone whose self-regarding concern is limited to parts of Dion, but no one whose self-regarding concern is limited to parts of Theon. Plausibly, anything that has concern of the distinctively selfregarding kind for Dion's left foot, and has it in a natural, normal way, has Dion's left foot as a part. Plausibly, any object of such concern is, eo ipso, part of the subject of the concern.

These are five striking differences between Dion and Theon. ${ }^{6}$ But do they really suffice to ground a difference with regard to thinkerhood? Theon is, at best, a rather cockeyed thinker, but are the differences truly sufficient to make Theon a non-thinker? For two reasons, it's plausible that they are.

First, the differences need not be as dramatic as one might imagine, because the difference to be grounded is not the difference between being a thinker and being devoid of thought. If Theon fails to be a thinker, it will still be true that thinking is present in Theon. Given the dominant theory of the relation between the mental and the cerebral - the tokentoken identity thesis - Theon is a container of thoughts (meaning that there are thoughts constituted by the activities of parts of Theon), even if Theon is not a subject of thoughts. That there is indeed such a distinction, one that would be explicated by reference to differences such as those cited above, seems especially plausible when considering such thoughtcontaining entities as these: (1) Aggregate, the aggregate consisting of Dion's brain, liver, and hands, (2) Gerrymander, the (non-scattered) part of Dion that consists of his central nervous system plus the first 3.17

\footnotetext{
${ }^{6}$ Note that analogues of differences (1) and (2) serve to distinguish Dion even from Adam, the part of Dion (if there actually is such a part) that consists of all of Dion except for a certain one of the atoms in Dion's left foot. There is this further, especially dramatic difference: Dion endures through decades of rapid mereological change (shedding hundreds of skin cells per second); Adam (unlike Theon) is mereologically rigid (for support, see Burke 2003) and therefore is either fleeting (if conceived as a hunk) or else fleetingly intact (if conceived as an aggregate). (Incidentally, hunks and aggregates make no special trouble for my view that no two objects coincide. See Burke 1994b, esp. 617-18.)
} 
centimetres of a certain 29 of the 62 spinal nerves that radiate from his spinal cord, and (3) the universe. (Are Aggregate, Gerrymander, and the universe deliberating about whether to go for a walk? Or is it rather that such deliberations are occurring within them?) Of course, not all philosophers allow the possibility, never mind the actuality, of such scattered or gerrymandered entities. But it's as reasonable to hold that counterpossibles differ in assertability as to hold that counterfactuals do. And I believe that most of those who deny the possibility of Aggregate, Gerrymander, and/ or the universe will want to assert that if they existed, they would be mere containers of thought, not subjects of thought.

Second, the differences will seem more than sufficient, if we assume, as we plausibly can, that the thinking within Dion is to be assigned to just one thing: either Dion or one of Dion's parts. (In a competition for a single prize or honour, as in an election or a horse race, there need be no dramatic difference - indeed, no more than a 'trivial' difference - separating the winner from the losers.) Why can we plausibly assume that just one thing thinks with Dion's brain? Well, the case is not like one of brain bisection. The thoughts of different thinkers would be constituted by numerically the same cerebral events. But it's extremely plausible that for every thought-constituting cerebral event there's one thought token, not many, that it constitutes, and extremely plausible that for every thought token there's one subject, not many, whose thought token it is. No doubt we could question these plausible propositions, if we had to. But since we can distinguish between subjects of thoughts and containers of thoughts, we don't have to.

To conclude: We can sustain the commonsensical view that proper parts of human thinkers are not themselves thinkers. In particular, we can defend the claim that Theon is initially a non-thinker. The amputation of Dion's left foot leaves a Theon-shaped object very similar microphysically to the pre-surgical Theon. But contrary to what many (including me) have said, the microphysical differences are far from insignificant. As a result of the microphysical differences, the object left by the surgery differs from the pre-surgical Theon in the same five ways that the pre-surgical Dion does. (It's an organism; the I-thoughts it contains are differentially true of it; it contains as a part everything in which the sensations it contains are felt; and so on.) And as a result of those differences, it differs also with regard to thinkerhood. The pre-surgical Theon is a non-man that neither perceives, emotes, nor reasons; and during the surgery it neither matures nor recovers from an incapacitating ailment. Theon's parts survive. But the object they compose after the surgery - a perceiving, emoting, reasoning man - is both sortally and psychologically discontinuous with Theon. It therefore does not strain credulity to say that Theon itself does not 
survive. Indeed, it strains credulity to say otherwise. The Theon-shaped object left by the surgery is, of course, Dion. ${ }^{7,8}$

Indiana University

Indianapolis, IN 46202, USA

mburke@iupui.edu

\section{References}

Burke, M. B. 1994a. Dion and Theon: an essentialist solution to an ancient puzzle. The Journal of Philosophy 91: 129-39.

Burke, M. B. 1994b. Preserving the principle of one object to a place: a novel account of the relations among objects, sorts, sortals, and persistence conditions. Philosophy and Phenomenological Research 54: 591-624.

Burke, M. B. 1997. Persons and bodies: how to avoid the new dualism. American Philosophical Quarterly 34: 457-67.

Burke, M. B. 2003. Is my head a person? In On Human Persons, ed. K. Petrus 10725. Frankfurt: Ontos-Verlag.

Carter, W. R. 1997. Dion's left foot (and the price of Burkean economy), Philosophy and Phenomenological Research 57: 371-79.

Geach, P. 1962. Reference and Generality. Ithaca: Cornell University Press.

Lewis, D. 1993. Many, but almost one. In Ontology, Causality and Mind: Essays in Honor of D. M. Armstrong, ed. J. Bacon, K. Campbell and L. Reinhardt, 22-38. Cambridge: Cambridge University Press.

Long, A. and D. Sedley. 1987. The Hellenistic Philosophers. Vol. 1. Cambridge: Cambridge University Press.

Lowe, E. J. 2002. A Survey of Metaphysics. Oxford: Oxford University Press.

Merricks, T. 2001 Objects and Persons. Oxford: Clarendon Press.

Noonan, H. W. 1999. Tibbles the cat: reply to Burke. Philosophical Studies 95: 215-18.

Olson, E. T. 1995. Why I have no hands. Theoria 61, Part 2: 182-97.

Olson, E. T. 1997. Dion's foot. The Journal of Philosophy 94: 260-65.

Rea, M. C. 2000. Constitution and kind membership. Philosophical Studies 97: 16993.

Sidelle, A. 2002. Is there a true metaphysics of material objects? Nôus. Special Issue 12: $118-45$.

Sider, T. 2001. Four-Dimensionalism. Oxford: Clarendon Press.

Stone, J. 2002. Why sortal essentialism cannot solve Chrysippus's puzzle. Analysis 62: 216-23.

van Inwagen, P. 1981. The doctrine of arbitrary undetached parts. Pacific Philosophical Quarterly 62: 123-37.

7 That Dion survives and Theon perishes was the view of Chrysippus, the Stoic philosopher who first posed the problem. (See Long and Sedley 1987: 171-72.) So, for the record, I do not 'deploy sortal essentialism against Chrysippus' (Stone 2002: 216). On the contrary, I deploy it in his defence.

${ }^{8}$ For valuable comments, I am grateful to John Tilley, Jason Eberl, and, especially, a referee for this journal. 